Marquette University

e-Publications@Marquette

College of Education Faculty Research and

Publications

Education, College of

11-1-2009

\title{
Treatment Outcomes for Toddlers with Behaviour Problems from Families in Poverty
}

Robert A. Fox

Marquette University, robert.fox@marquette.edu

Casey A. Holtz

Marquette University

Accepted version. Child and Adolescent Mental Health, Vol. 14, No. 4 (November 2009): 183-189.

DOI. (C) 2009 Wiley-Blackwell. Used with permission.

The definitive version is available at www3.interscience.wiley.com. 


\title{
Treatment Outcomes for Toddlers with Behavior Problems from Families in Poverty
}

\author{
Robert A. Fox \\ Department of Counseling and Educational Psychology \\ College of Education \\ Marquette University \\ Milwaukee WI \\ Casey A. Holtz \\ Department of Counseling and Educational Psychology \\ College of Education \\ Marquette University \\ Milwaukee WI
}

\section{Footnote:}

Robert A. Fox and Casey A. Holtz, Department of Counseling and Educational Psychology, College of Education, Marquette University, Milwaukee WI.

This research was supported in part by grants from the Assurant Health Foundation, Charles D. Jacobus Family Foundation, Exchange Club, and United Way. The authors acknowledge the support of Penfield Children's Center, the Birth-to-Three Agency that served as the site for this study, and the graduate students who provided mental health services for the toddlers and their families. 
NOT THE PUBLISHED VERSION; this is the author's final, peer-reviewed manuscript. The published version may be accessed by following the link in the citation at the bottom of the page.

Correspondence concerning this article should be addressed to Robert A. Fox, Marquette University, Department of Counseling and Educational Psychology, College of Education, Schroeder Complex, P. O. Box 1881, Milwaukee WI 53201-1881. E-mail: robert.fox@marquette.edu; Phone: 414288-1469.

\begin{abstract}
:
Background. Relatively few treatment studies address mental health issues in very young children. This study examined the effectiveness of a treatment program for toddlers whose behavior problems were further complicated by living in poverty. Method. An empirically-validated treatment program was adapted for use in the homes of 102 toddlers for an average of 12 weekly sessions.

Results. Significant improvements were found for the children's behavior problems and their compliance to parent requests.

Discussion. The inherent challenges in working with at-risk families and the challenges in delivering mental health services for very young children living in poverty are discussed.
\end{abstract}

Key Words: toddlers, behavior problems, delays, poverty, treatment

\title{
Treatment Outcomes for Toddlers with Behavior Problems from Families in Poverty
}

Challenging behaviors are common during the toddler and preschool years and for some children, they may escalate into severe tantrums, self-injury, aggression, destructiveness, oppositional behavior and hyperactivity. Campbell (1995) reported that between $10-15 \%$ of young children have mild to moderate behavior problems that may persist well into the child's formal school years (Campbell, 1997), increase in severity (Hofstra, Van Der Ende, \& Verhulst, 2002), adversely affect the children's relationship with caregivers (Greene \& Doyle, 1999), and interfere with their development of social (Mendez, Fantuzzo, \& Cicchetti, 2002) and communication skills (Sigafoos, 2000). Young children's behavior problems also have been associated with higher levels of parental stress (Eyberg, Boggs, \& Rodriguez, 1992).

There are a number of factors that contribute to the onset, escalation and persistence of behavior problems in young children. In their review, Huaqing Qi and Kaiser (2003) reported that preschool children from low-income families had a significantly higher incidence of behavior problems (31\%) than those in the general population. To better understand this relationship of behavior problems and poverty, Fox, Platz, and Bentley (1995) found that younger, single, less-

Child and Adolescent Mental Health, Vol. 14, No. 4 (November 2009): pg. 183-189. DOI. This article is @ Wiley and permission has been granted for this version to appear in e-Publications@Marquette. Wiley does not grant permission for this article to be further copied/distributed or hosted elsewhere without the express permission from Wiley. 
educated mothers from lower-income levels tended to use more frequent verbal and corporal punishment when parenting their young children who also had more behavior problems. Brenner and Fox (1998) reported that the best predictor of behavior problems in young children was parental use of verbal and corporal punishment. This relationship between behavior problems in children and harsh parenting practices was also reported in other research (Baker \& Heller, 1996; Nix et al., 1999); however, the direction of this relationship is not clear. That is, do behavior problems elicit harsh parenting practices or do harsh parenting practices result in behavior problems? In addition to negative parenting practices, a young child with developmental delays is at an increased risk for having behavior problems (Feldman et al., 2000; Roberts et al., 2003). Baker et al. (2002) found that children with delays were three to fours times more likely to obtain clinically significant scores on a child behavior scale than their non-disabled peers. Einfeld and Tonge (1996) reported that $41 \%$ of children with intellectual delays had severe behavior and emotional problems.

A number of empirically-validated parent management programs have emerged to address the mental health needs of young children using developmentally-appropriate treatment strategies (Eyberg, Boggs, \& Algina, 1995; Fox \& Nicholson, 2003; Sanders, Mazzucchelli, \& Studman, 2003; Webster-Stratton, 2001). However, relatively few of these programs address very young children living in poverty. In one study including 882 children in Head Start programs, Reid, Webster-Stratton, and Baydar (2004) reported significant improvements in the children's behavior problems following caregiver participation in a group-based, parenting program. Nicholson, Brenner, and Fox (1999) provided a 10-week, group-based program of parent management training in community-based, nonprofit agencies for 143 children and their mothers. Results showed that parents were more nurturing and used less corporal and verbal punishment with their young children; also children's problem behaviors reduced significantly. In a controlled study of low-income parents who reported frequent pre-treatment use of corporal and verbal punishment with their young children, Nicholson et al. (2002) reported significant post treatment reductions in these negative parenting practices, parental anger, parent distress, and child behavior problems.

Child and Adolescent Mental Health, Vol. 14, No. 4 (November 2009): pg. 183-189. DOI. This article is (c) Wiley and permission has been granted for this version to appear in e-Publications@Marquette. Wiley does not grant permission for this article to be further copied/distributed or hosted elsewhere without the express permission from Wiley. 
Fewer studies addressed children with developmental delays. In a U.S. Department of Education survey (2002) of children enrolled in early intervention programs, less than 3\% received any mental health services at all. Roberts et al. (2006) implemented a parenting program in a clinic setting for families with preschoolers who were mildly delayed with behavior problems. The outcomes included improvements in the children's behavior and parent-child interactions and reduced parental stress. Similarly, group adaptations of Parent-Child Interaction Therapy (Eyberg et al., 1995) and the Incredible Years Parent Training series (Webster-Stratton, 2001) for parents of young children with developmental delays demonstrated improvements in child compliance, behavior problems, and parenting practices (Bagner \& Eyberg, 2007; McIntyre (2008). The majority of treatment studies involving young children with behavior problems used a group-based, parent education class format in clinics or community-based sites.

Families living in poverty often experience significant barriers that limit their access to such programs including transportation difficulties, caring for multiple children, problems keeping schedule appointments, and reduced motivation (Snell-Johns, Mendez \& Smith, 2004). As such, this traditional model of delivering parent management programs may not meet the needs of these families.

The purpose of the present study was to examine the effectiveness of a parent treatment program for very young children with behavior problems, most of whom also had significant developmental delays and were living in poverty. The treatment program was adapted from an existing parenting program with proven efficacy (Fox \& Nicholson, 2003). Because of the multiple barriers these families living in poverty face in accessing mental health services, the program was designed to be individually delivered to families in their homes.

\section{Method}

\section{Participants}

Study participants were children referred to a mental health clinic that specialized in providing home-based services for families of toddlers with developmental delays and significant behavior problems (Fox et al., 2007). Of 238 families who completed intake evaluations, 102 completed the treatment program (57\% attrition rate). Families

Child and Adolescent Mental Health, Vol. 14, No. 4 (November 2009): pg. 183-189. DOI. This article is @ Wiley and permission has been granted for this version to appear in e-Publications@Marquette. Wiley does not grant permission for this article to be further copied/distributed or hosted elsewhere without the express permission from Wiley. 
who completed the treatment program had children who were significantly younger $(M=2.66, S D=0.74)$ than non-completers $(M=$ $2.94, S D=0.93)[t(181)=2.08, p=.04]$. African American children, who comprised the largest group in the sample (54\%), were more likely to terminate treatment prematurely (59\%) than children who were Caucasian (35\%), Latino (34\%) or of mixed ethnicity $(36 \%)\left[X^{2}\right.$ (3) $=11.47, p=.009]$. Also caregivers in the completer's group were more likely to be married $(38 \%)$ than non-completers $(24 \%)\left[X^{2}(1)=\right.$ $7.89, p=.007]$. There were no significant differences between completers and non-completers on any of the study's other continuous variables (parent age, parent education, or number of children living at home) or the non-continuous variables (children's gender, presence of a developmental delay, reason for referral, psychiatric diagnoses, or the primary caregiver's economic or employment status).

The sample of treatment completers included 59 boys and 43 girls (43\% African American, 21\% Latino, 21\% Caucasian, and 15\% mixed ethnicity or other) who ranged in age from 1 to 5 years ( $M=$ 2.66 years, SD $=0.74$ years $) ; 70 \%$ of the sample also met the criteria for a significant developmental delay that was defined as being at least $25 \%$ behind their chronological age in one more areas of development (e.g., cognition, language, motor). Most children were referred for severe tantrums, aggression, and oppositional behavior. The primary caretakers for these children were usually their biological mothers $(84 \%)$, most of whom were unmarried (62\%) and unemployed (54\%), had less than a high school education ( $M$ years in school $=11.92, S D$ $=2.59$ ), and were receiving one or more sources of public assistance $(85 \%)$, which required that their annual family income was below the federal poverty level. The primary caretakers were caring for an average of three children in their homes $(S D=1.41$; range $=1-8$ ).

\section{Procedures}

All participants signed an informed consent form, approved by the university's Institutional Review Board, prior to initiating the intake evaluation and treatment program. Treatment policies were shared with the families at the intake session and included the need for the caregiver and child to be present for all sessions and that sessions were to be as distraction free as possible (no TV, visitors, phone calls). The treatment procedures were predicated on clinicians establishing a trusting, collaborative relationship with the child's primary caregiver.

Child and Adolescent Mental Health, Vol. 14, No. 4 (November 2009): pg. 183-189. DOI. This article is @ Wiley and permission has been granted for this version to appear in e-Publications@Marquette. Wiley does not grant permission for this article to be further copied/distributed or hosted elsewhere without the express permission from Wiley. 
In part, this meant that clinicians often discussed issues with families that were not directly related to the treatment procedures (e.g., caregiver's mental health issues, relationship problems, neighborhood safety, child referrals for school programs and needed medical evaluations). This inclusion of non-treatment issues is consistent with the experiences of others providing parent management training, who reported that up to one-third of their time may be taken up with the caregivers' other family concerns (Patterson \& Narrett, 1990).

Parent Management Training. The treatment program was adapted from the empirically-validated Parenting Young Children Program (Fox \& Nicholson, 2003). The core treatment components and procedures remained the same as the original program. The adaptations primarily involved simplifying the program contents to ensure that all of the caregivers understood the program's content and procedures. Treatment sessions were scheduled weekly in the children's homes and lasted approximately 60 to 90 minutes. As a first step towards strengthening their relationship with their young children, parents were taught to engage their children in non-directive play. This method of play encourages the child rather than the parent to lead the play. The parent's role is to participate in and positively comment on the child's play. Parents were encouraged to engage in this form of play at least daily for a minimum of 15 minutes. The premise for introducing this play component early in treatment was twofold: (1) often the quality of the parent-child relationship had deteriorated due to the child's significant behavior problems; and (2) the treatment program's effectiveness could be enhanced by redeveloping a stronger parent-child relationship through play. Following the non-directive play, four additional treatment components were introduced in the following order: (a) teaching the parents to thoughtfully interact with their children rather than emotionally overreact to their children's challenging behaviors; (b) helping the parents to learn and maintain appropriate developmental expectations for their child; (c) using techniques such as positive reinforcement, establishing home routines, and giving good instructions to strengthen the child's prosocial behaviors; and (d) employing limit-setting strategies such as redirection, ignoring, response cost, and time-out to reduce the child's challenging behaviors. Each treatment strategy was explained to the caregiver and directly modeled by the clinician. Parents also practiced each strategy with their children and received

Child and Adolescent Mental Health, Vol. 14, No. 4 (November 2009): pg. 183-189. DOI. This article is (c) Wiley and permission has been granted for this version to appear in e-Publications@Marquette. Wiley does not grant permission for this article to be further copied/distributed or hosted elsewhere without the express permission from Wiley. 
immediate feedback from the clinician. All materials needed to implement the treatment plan were provided by the clinician (e.g., parent handouts, edible reinforcers, stickers, door gates for time-out). Each session concluded with the clinician providing the caregiver with a behavior plan that included an abbreviated list of the treatment steps that were to be followed until the next session. For example, the list might include: (1) play with Billy for 10 minutes right before supper; (2) give Billy five simple requests during the day such as "pick up the toy" or "come here" and provide an immediate edible reward and praise each time; and (3) use a one minute time-out when Billy hits his younger sister. The plan included a place to mark whether the caregiver implemented the treatment program each day. Caregivers who completed the behavior plan's documentation form and had it ready in time for the next session were provided a $\$ 5$ gift certificate to use at a local grocery store. This incentive was considered necessary to enhance the caregivers' level of motivation to participate in the program and was especially salient for families with very limited financial resources. As the parents observed their child's behavior problems improving over the course of treatment, the need for continued incentives was expected to diminish.

Clinician Training. Clinicians were 12 master's level graduate students in counseling and psychology programs who received practicum and internship course credit for their participation in this program. A doctoral level psychologist and two doctoral psychology students provided the training and supervision of the clinicians. All clinicians received extensive training and supervision regarding how to interact with a diverse population of families, including poorly educated parents and families living in poverty and unsafe neighborhoods. All clinicians received didactic training in the treatment procedures that were detailed in a training manual adapted from Fox \& Nicholson (2003). Clinicians initially shadowed more veteran clinicians doing the home-based parent management program and then gradually assumed the role of a clinician. All clinicians were observed implementing the treatment program and successfully met the treatment integrity criteria prior to leading treatment cases on their own. These criteria included having appropriate professional demeanor (objectivity, punctuality), being sensitive to family's culture and level of understanding, establishing home visit guidelines with the caregiver, accurately explaining and demonstrating all treatment procedures,

Child and Adolescent Mental Health, Vol. 14, No. 4 (November 2009): pg. 183-189. DOI. This article is @ Wiley and permission has been granted for this version to appear in e-Publications@Marquette. Wiley does not grant permission for this article to be further copied/distributed or hosted elsewhere without the express permission from Wiley. 
providing caregiver feedback, and timely paperwork. Each family was assigned two clinicians who were present for the home-based sessions, in part for safety reasons. The lead clinician was responsible for implementing all treatment sessions from intake through treatment completion; the support clinician worked with the child and collected reliability data for the study's measures. Infrequently, families were transferred to a different clinician when a clinician's placement at the clinic was over. Each clinician participated in weekly individual and group supervision meetings to receive assistance on specific issues that arose with families and for feedback on the clinician's performance.

\section{Evaluation Instruments}

The assessment measures described below, with the exception of the family satisfaction survey, were completed at intake and again at the conclusion of the final treatment session.

Parent-Child Interactions. Parents were instructed to play with their children for 15-20 minutes while the clinician observed and rated the quality of the parent and child interaction. Based on the work of Crawley and Spiker (1983), five dimensions of the child's behavior (positive affect, negative affect, interest in play, initiates interactions, socially responsive), and six dimensions of the parent's behavior (parent directs play, parent lets child direct play, sensitivity to child, expectations for child, discipline - sets appropriate limits, and reciprocity) were rated using a five point frequency scale ( $1=$ never, 2 = seldom, 3 = average, $4=$ usually, $5=$ always). Separate total scores were computed for the five dimensions of the child's behaviors (the negative affect item scores were reversed for this computation) and the six dimensions of the parent's behaviors (the parent leads item scores were reversed for this computation). For the present sample, coefficient alphas were computed for the child (.75) and parent behavior scores (.71). Inter-rater reliabilities were computed for $30 \%$ of the sample and resulted in significant correlations for the child (.76) and parent behavior scores (.75).

Child's compliance. Parents were told to give their child five standard requests to assess how well their children listened to them (e.g., pick up the toy, come here). After recording the number of parental requests and the child's compliance (yes or no), a compliance percentage score was computed. For approximately $30 \%$ of the

Child and Adolescent Mental Health, Vol. 14, No. 4 (November 2009): pg. 183-189. DOI. This article is @ Wiley and permission has been granted for this version to appear in e-Publications@Marquette. Wiley does not grant permission for this article to be further copied/distributed or hosted elsewhere without the express permission from Wiley. 
observations, two clinicians independently completed the compliance assessment. Correlations between observers were .94 for the total number of parental requests and .96 for the total number of times the child complied with parent requests. Using a three point scale ( $0=$ seldom/never, 1 =sometimes, 2 =frequently/always), observers also rated how often the parents used their child's name before giving a request and how often parents provided praise for their child's compliance.

Eyberg Child Behavior Inventory (ECBI). The ECBI (Eyberg \& Pincus, 1999) is a 36-item inventory that measures behavior problems common in children. Parents rate the frequency of each behavior problem on a scale from 1 (never) to 7 (always), resulting in an Intensity Score (range $=36-252)$, and whether or not $($ no=0, yes $=1$ ) they consider the behavior to be a problem for them resulting in a Problem Score (range $=0-36$ ). The ECBI has been shown to discriminate between children with and without clinically significant behavior problems (Weis, Lovejoy, \& Lundahl, 2004). Evidence of reliability for the intensity and problem scores, respectively was: internal consistency $=.95, .93$; test-retest $=.80, .85$; and inter-rater $=.86, .79$.

Parent Behavior Checklist (PBC). The PBC (Fox, 1994) is a 32item rating scale designed to measure the behaviors and expectations of parents of young children 1-5 years of age. The PBC consists of three scales: Expectations - 12 items that measure parents' developmental expectations ("My child should be able to feed him/herself"); Discipline - 10 items that assess parental responses to children's problem behaviors ("I yell at my child for spilling food"); and Nurturing - 10 items that measure specific parent behaviors that promote a child's psychological growth ("I read to my child at bedtime"). The range of total scores for each subscale are: Expectations (12-48) with higher scores indicating higher parental expectations; Discipline (10-40) with higher scores indicating more frequent use of verbal and corporal punishment (e.g., yelling, spanking); and Nurturing (10-40) with higher scores suggesting more frequent use of positive nurturing activities. The following internal consistencies and test-retest reliabilities, respectively, were reported: Expectations $=.97, .98 ;$ Discipline $=.91, .87$; and Nurturing $=.82$, .81 .

Child and Adolescent Mental Health, Vol. 14, No. 4 (November 2009): pg. 183-189. DOI. This article is @ Wiley and permission has been granted for this version to appear in e-Publications@Marquette. Wiley does not grant permission for this article to be further copied/distributed or hosted elsewhere without the express permission from Wiley. 
NOT THE PUBLISHED VERSION; this is the author's final, peer-reviewed manuscript. The published version may be accessed by following the link in the citation at the bottom of the page.

Parent-Child Relationship Scale. This scale provides a global assessment of the quality of the parent and child relationship on a scale of 0-100 with five behavioral anchors at 20-point intervals (Fox \& Nicholson, 2003).

Psychiatric diagnosis. The Kiddie Schedule for Affective Disorders and Schizophrenia for School-Aged Children (K-SADS-PL; Kaufman et al., 1997) was completed to determine whether the child met a psychiatric diagnosis included in the Diagnostic and Statistical Manual of Mental Disorders (DSM-IV; APA, 2000). The K-SADS-PL is a semi-structured interview designed to assess current and past episodes of psychopathology in children. Probes are used to elicit the information necessary to score each item. The K-SADS-PL was completed at intake and again at the conclusion of the treatment program.

Family satisfaction survey. A seven-item survey was used to assess the parent's satisfaction with the parent management program. Using a 7-point Likert-type rating scale, parents were asked to rate the quality of the program, how the program contributed to the child's improvement, how the program helped parents improve how they managed their children, if parents would use the clinic again if needed, the current status of child's referral concern, if the parents would recommend the clinic's program to others, and the parents' confidence in managing their children's behavior in the future. Based on the present sample, the internal consistency for these seven items was $r=$ .77 .

\section{Results}

At intake, families who completed the treatment program did not differ from families who were non-completers on any of the study's outcome measures. Completers participated in an average of 12.76 weekly, in-home sessions $(S D=5.30)$ over a mean of 4.91 months $(S D=2.57)$ with an average attendance rate of $79.2 \%(S D=14.99)$. Non-completers participated in an average of 3.92 sessions ( $S D=$ $4.48)$ over a mean of 3.64 months $(S D=3.17)$ with an average attendance rate of $51.6 \%(S D=36.37)$. Completers and noncompleters significantly differed on all three participation measures ( $p$ $<.05)$.

Although treatment completers participated in the intake and post-treatment evaluations, missing data for the study's measures

Child and Adolescent Mental Health, Vol. 14, No. 4 (November 2009): pg. 183-189. DOI. This article is @ Wiley and permission has been granted for this version to appear in e-Publications@Marquette. Wiley does not grant permission for this article to be further copied/distributed or hosted elsewhere without the express permission from Wiley. 
occurred for a variety of reasons. The child's significant oppositional behavior often precluded their participation in the direct observational measures. Additionally, some parents refused to play with their children to allow us to observe and rate the quality of the parent-child interactions. There were situations where clinicians chose to initiate treatment at the expense of data collection because the child's behavior was sufficiently severe to cause harm. At times, the numbers of different people present in the home jeopardized the confidentiality of the caregiver or created a noisy and chaotic atmosphere that was not suited for data collection. For some families, the caregivers did not understand the self-report instruments, thus invalidating their responses.

For the treatment completers, repeated measures, multivariate analyses of variance (MANOVA) were used to assess changes from intake to treatment completion. Significant MANOVAs were followed up with univariate $F$ tests to determine the source of the significance (Table 1). The first MANOVA was computed for the observational measures of the parent-child interactions and revealed a significant time effect $[F(2,65)=22.37, p<.01]$ with a moderate effect size (.41), which was due to significant improvement in both the child and parent behavior scores. A significant time effect also was found for the children's compliance, parent use of the child's name and the parent complimenting the child during compliance testing $[F(3,46)=17.19, p$ $<.01]$; the effect size was moderate (.53). Based on the ECBI, children's behavior problems improved significantly over time $[F(2,89)$ $=39.35, p<.001$ ] with a moderate effect size (.47) that was due to significant decreases in both the intensity and number of children's problem behaviors. The Parent Behavior Checklist showed significant change over time $[F(3,81)=7.39, p<.001]$ with a small effect size (.22.) that was due to a significant increase in parent expectations.

\section{Clinical Significance}

Eyberg and Pincus (1999) recommended a $t$-score of 60 as a cutoff score to determine if the child's scores on the ECBI's intensity and problems scales were clinically significant. The proportion of children who met the cutoff score at intake but not at treatment completion changed significantly for the intensity $\left(X^{2}(1)=17.41, p<\right.$ $.001)$ and problem scores $\left(X^{2}(1)=18.08, p<.001\right)$. For the intensity measure, $64.5 \%$ met the cutoff criteria at intake compared to $47.3 \%$

Child and Adolescent Mental Health, Vol. 14, No. 4 (November 2009): pg. 183-189. DOI. This article is (C) Wiley and permission has been granted for this version to appear in e-Publications@Marquette. Wiley does not grant permission for this article to be further copied/distributed or hosted elsewhere without the express permission from Wiley. 
at treatment completion; for the problem measure, $63.7 \%$ met the cutoff criteria at intake compared to $34.1 \%$ at treatment completion

Of the children who received a formal DSM Axis I psychiatric diagnosis at intake, 79.3\% were oppositional defiant disorder, $8.5 \%$ separation anxiety disorder, $2.4 \%$ attention deficit hyperactivity disorder, and the remaining $9.8 \%$ were other disorders (autism, conduct disorder, reactive attachment disorder). At intake, $82.7 \%$ of the sample received a psychiatric diagnosis; at the end of treatment, $21.4 \%$ of the children met the criteria for a psychiatric diagnosis.

\section{Family Satisfaction}

In order to assess caregiver satisfaction with the parent management program, total scores were computed by summing the parent ratings for the seven items comprising this scale with a possible range of scores from 7 (low satisfaction) to 49 (high satisfaction). The average score on this measure was $44.40(S D=4.00)$.

\section{Discussion}

The results of this study demonstrated that the parent management program was an effective intervention program for toddlers with behavior problems living in poverty. Parent-child interactions improved from pre- to post-treatment based on direct observations of the parents and children in their homes. Not only did the quality of their interactions and reciprocity improve, but children's compliance to parental requests also increased significantly. The latter finding may be due to the parents' improving their skills at obtaining their child's attention before giving a request and following their child's compliance with social rewards. These direct observational data of improvement in the children's behaviors are particularly compelling as very young children normally will not "fake" behaviors to present themselves in a socially desirable manner. Consequently, observing these young children in their natural settings, while inherently challenging for optimal data collection, provided a reliable and valid method for assessing change.

The study's findings also indicated that the parent treatment program was associated with significant reductions in the frequency and severity of the children's behavior problems. The effect sizes for these pre to post treatment changes were moderate which is consistent with other research (Behan \& Carr, 2000; McIntyre, 2008).

Child and Adolescent Mental Health, Vol. 14, No. 4 (November 2009): pg. 183-189. DOI. This article is @ Wiley and permission has been granted for this version to appear in e-Publications@Marquette. Wiley does not grant permission for this article to be further copied/distributed or hosted elsewhere without the express permission from Wiley. 
Parents also increased their expectations for their children over the course of treatment. The increase may be due to parents adjusting their expectations to the child's developmental growth over the course of treatment (average of five months). In addition, unreasonable parental expectations were consistently challenged throughout treatment. Parental discipline scores did not change at post treatment which is not consistent with previous research (Nicholson, et al. 1999; 2002). This finding may be due in part to the parents' reluctance to honestly share their negative parenting practices at intake with an unfamiliar clinician, perhaps in part out of a fear of being reported to the authorities for child abuse. Throughout treatment, clinicians did report increased parental use of effective limit setting strategies (timeout). The majority children with a psychiatric diagnosis at intake no longer met the criteria at for a psychiatric diagnosis at treatment completion. This finding supports providing early intervention for children before their behavior patterns become more resistant to change. Parents reported high levels of satisfaction with the treatment services. These results support the findings from the literature regarding the effectiveness of behavioral family interventions for young children with behavior problems and developmental disabilities (Gavidia-Payne \& Hudson, 2002).

One limitation of the present study was the absence of a control group. The efficacy of the treatment strategies that were employed in this study has been well established in the literature. However to our knowledge, no effort has been made to apply these strategies to very young children with delays and behavior problems from families in poverty in their home settings. While we had initially intended to include a wait-list control group, we quickly learned that this would not be reasonable given the significant difficulty we experienced in initially engaging our families and in maintaining them throughout the treatment program. Our treatment attrition rate of $57 \%$, which is higher than the 33\% reported in other treatment studies for families of children with developmental disabilities (Roberts et al., 2006) and the $50 \%$ rate for children from low-income families (Nicholson et al., 1999), exemplifies the inherent challenges of providing mental health services to this population. Our analyses of family intake data also suggested that it would be difficult to identify those families who were likely to benefit from the parenting program based on this information alone. We also did not include a follow-up condition to determine if the

Child and Adolescent Mental Health, Vol. 14, No. 4 (November 2009): pg. 183-189. DOI. This article is @ Wiley and permission has been granted for this version to appear in e-Publications@Marquette. Wiley does not grant permission for this article to be further copied/distributed or hosted elsewhere without the express permission from Wiley. 
treatment effects were maintained over time. We are presently engaged in a follow-up study that will essentially repeat the study's outcome measures one to three years after treatment completion. However, we are already finding this study has inherent limitations. One characteristic of our families is their transient nature. In addition to moving frequently, families routinely have their telephone services. Consequently, locating these families for follow-up has been challenging.

The sample for this study was somewhat heterogeneous including young boys and girls with and without developmental delays, families living in and not in poverty, caregivers with and without marital support systems, and different ethnic groups. The treatment program selected for this study has been previously empirically validated for all of these child and family variables with the exception of the presence of a developmental delay. In a recent study comparing this treatment program between children with and without delays and behavior problems (Holtz, Carrasco, Mattek, \& Fox, 2008), results showed that the parent management program was equally effective for both groups. Consequently, practitioners should feel confident in using this treatment program with young children coming from a variety of different family backgrounds.

This treatment program included several components including non-directive play, teaching parents to monitor their thoughts and feelings when interacting with their child, instructing caregivers on how to maintain appropriate developmental for their children, procedures to strengthen children's prosocial behaviors, limit setting strategies, and parent incentives. In addition, this program was tailored to meet the unique circumstances of each family and delivered in their homes. The study's design did not permit us to ferret out the unique contributions of the separate treatment components to the program's effectiveness. However, the use of multiple strategies to address the myriad of child, family, and environmental factors that contribute to behavior problems in young children is consistent with other programs reported in the literature (Eyberg, Boggs, \& Algina, 1995; Sanders, Mazzucchelli, \& Studman, 2003; Webster-Stratton, 2001), and most importantly, shares their adherence to a foundation in social learning theory and cognitive behavioral treatment approaches.

Child and Adolescent Mental Health, Vol. 14, No. 4 (November 2009): pg. 183-189. DOI. This article is (c) Wiley and permission has been granted for this version to appear in e-Publications@Marquette. Wiley does not grant permission for this article to be further copied/distributed or hosted elsewhere without the express permission from Wiley. 
Clearly, engaging these at risk families in early mental health intervention efforts is important. In the absence of quality parental involvement, many young children who need these mental health services will not receive them in the early childhood period, when they are likely to have their greatest impact. New strategies will be needed to identify these children with significant behavior problems as early as possible and to attempt to overcome family barriers that will interfere with their participation in treatment. New research is emerging to help screen for these early behavior problems in very young children from low-income families (Holtz, Fox, \& Meurer, 2008) and to begin to more systematically address barriers to treatment attendance and adherence (Nock \& Ferriter, 2005). The present study showed that families who drop out of treatment did so around the fourth session. We currently have modified our parent incentive system to provide a larger incentive after the third session and an even larger one at treatment completion rather than smaller incentives at each treatment session to increase caregivers' motivation to complete the treatment program. We know how to effectively change young children's behavior problems. Now we have to get better at engaging families who resist our treatment efforts.

\section{References}

American Psychiatric Association (2000). Diagnostic and statistical manual of mental disorders, Fourth Edition, Text Revision. Washington, D.C.: Author.

Bagner, D. M., \& Eyberg, S. M. (2007). Parent-child interaction therapy for disruptive behavior in children with mental retardation: A randomized controlled trial. Journal of Clinical Child and Adolescent Psychology, 36, 418-429.

Baker, B. L., Blacher, J., Crnic, K. A., \& Edelbrock, C. (2002). Behavior problems and parenting stress in families of three-year-old children with and without developmental delays. American Journal on Mental Retardation, 107, 433-444.

Baker, B. L., \& Heller, T. L. (1996). Preschool children with externalizing behaviors: Experience of fathers and mothers. Journal of Abnormal Child Psychology, 24, 513-532.

Behan, J., \& Carr, A. (2000). Oppositional defiant disorder. In A. Carr (Ed.), What works for children and adolescents? A critical review of psychological interventions with children, adolescents and their families. London: Routledge.

Child and Adolescent Mental Health, Vol. 14, No. 4 (November 2009): pg. 183-189. DOI. This article is (c) Wiley and permission has been granted for this version to appear in e-Publications@Marquette. Wiley does not grant permission for this article to be further copied/distributed or hosted elsewhere without the express permission from Wiley. 
NOT THE PUBLISHED VERSION; this is the author's final, peer-reviewed manuscript. The published version may be accessed by following the link in the citation at the bottom of the page.

Brenner, V., \& Fox, R. A. (1998). Parental discipline and behavior problems in young children. The Journal of Genetic Psychology, 159, 251-256.

Campbell, S. B. (1995). Behavior problems in preschool children: A review of recent research. Journal of Child Psychology \& Psychiatry, 36, 113149.

Campbell, S. B. (1997). Behavior problems in preschool children: Developmental and family issues. Advances in Clinical Child Psychology, 19, 1-26.

Crawley, S. B., \& Spiker, D. (1983). Mother-child interactions involving twoyear-olds with Down syndrome: A look at individual differences. Child Development, 54, 1312-1323.

Einfeld, S. L., \& Tonge, B. J. (1996). Population prevalence of psychopathology in children and adolescents with intellectual disability II: Epidemiological findings. Journal of Intellectual Disability Research, 40, 99-109.

Eyberg, S. M., Boggs, S., \& Algina, J. (1995). Parent-child interaction therapy: A psychosocial model for the treatment of children with conduct problem behavior and their parents. Psychopharmacology Bulletin, 31, 83-91.

Eyberg, S. M., Boggs, S. R., \& Rodriguez, C. M. (1992). Relationships between maternal parenting stress and child disruptive behavior. Child and Family Behavior Therapy, 14, 1-9.

Eyberg, S. M., \& Pincus, D. (1999). Eyberg Child Behavior Inventory and the Sutter-Eyberg Student Behavior Inventory-Revised. Lutz, FL: Psychological Assessment Resources, Inc.

Feldman, M. A., Hancock, C. L., Rielly, N., Minnes, P., \& Cairns, C. (2000). Behavior problems in young children with or at risk for developmental delay. Journal of Child and Family Studies, 9, 247-261.

Fox, R. A. (1994). Parent Behavior Checklist. Austin, TX: ProEd (Currently available from the author, Marquette University, School of Education, P.O. Box 1881, Milwaukee, WI 53201-1881; Email:robert.fox@marquette.edu).

Fox, R. A., Keller, K. M., Grede, P. L., \& Bartosz, A. M. (2007). A mental health clinic for Toddlers with developmental delays and behavior problems. Research in Developmental Disabilities, 28, 119-129.

Fox, R. A., \& Nicholson, B. C. (2003). Parenting young children: A facilitator's guide. Longmont, CO: Sopris West.

Fox, R. A., Platz, D. L., \& Bentley, K. S. (1995). Maternal factors related to parenting practices, developmental expectations, and perceptions of child behavior problems. The Journal of Genetic Psychology, 156, 431441.

Gavidia-Payne, S., \& Hudson, A. (2002). Behavioral supports for parents of children with an intellectual disability and problem behaviors: An

Child and Adolescent Mental Health, Vol. 14, No. 4 (November 2009): pg. 183-189. DOI. This article is @ Wiley and permission has been granted for this version to appear in e-Publications@Marquette. Wiley does not grant permission for this article to be further copied/distributed or hosted elsewhere without the express permission from Wiley. 
overview of the literature. Journal of Intellectual and Developmental Disability, 27, 31-55.

Greene, R.W., \& Doyle, A.E. (1999). Toward a transactional conceptualization of oppositional defiant disorder: Implications for assessment and treatment. Clinical Child and Family Psychology Review, 2, 129-148.

Hofstra, M. B., Van der Ende, J., \& Verhulst, F. C. (2002). Pathways of selfreported problem behaviors from adolescence into adulthood. American Journal of Psychiatry, 159(3), 401-407.

Holtz, C. A., Carrasco, J. M., Mattek, R. J., \& Fox, R. A. (2008). Behavior problems in toddlers with and without developmental delays: Comparison of treatment outcomes. Manuscript submitted for publication.

Holtz, C. A., Fox, R. A., \& Meurer, J. (May, 2008). Patterns of behavior problems among urban toddlers and preschoolers and development of a new survey tool. Paper presented at the international meeting of the Pediatric Academic Society in Honolulu, Hawaii.

Huaqing Qi, C., \& Kaiser, A. P. (2003). Behavior problems of preschool children from low-income families: Review of the literature. Topics in Early Childhood Special Education, 23, 188-216.

Kaufman, J., Birmaher, B., Brent, D., Rao, U., Ryan, N., Flynn, C., \& Moreci, P. (1997). The Revised Schedule for Affective Disorders and Schizophrenia for School Aged Children: Present and Lifetime Version: Preliminary reliability and validity data. Journal of the American Academy of Child and Adolescent Psychiatry, 36, 980-988.

McIntyre, L. L. (2008). Parent training for young children with developmental disabilities: Randomized controlled trial. American Journal on Mental Retardation, 113, 356-358.

Mendez, J.L., Fantuzzo, J., \& Cicchetti, D. (2002). Profiles of social competence among low-income African American preschool children. Child Development, 73, 1085-1101.

Nicholson, B., Anderson, M., Fox, R., \& Brenner, V. (2002). One family at a time: A prevention program for at-risk parents. Journal of Counseling \& Development, 80, 362-371.

Nicholson, B. C., Brenner, V., \& Fox, R.A. (1999). A community-based parenting program with low-income mothers of young children. Families in Society: The Journal of Contemporary Human Services, 80, 247-253.

Nix, R. L., Pinderhughes, E. E., Dodge, K. A., Bates, J. E., Pettit, G. S., \& McFadyen-Ketchum, S. A. (1999). The relation between mother's hostile attribution tendencies and children's externalizing behavior problems: The mediating role of mother's harsh discipline practices. Child Development, 70, 896-909.

Child and Adolescent Mental Health, Vol. 14, No. 4 (November 2009): pg. 183-189. DOI. This article is (C) Wiley and permission has been granted for this version to appear in e-Publications@Marquette. Wiley does not grant permission for this article to be further copied/distributed or hosted elsewhere without the express permission from Wiley. 
NOT THE PUBLISHED VERSION; this is the author's final, peer-reviewed manuscript. The published version may be accessed by following the link in the citation at the bottom of the page.

Nock, M. K. \& Ferriter, C. (2005). Parent management of attendance and adherence in child and adolescent therapy: A conceptual and empirical review. Clinical Child and Family Psychology Review, 8, 149-166.

Patterson, G. R., \& Narrett, C. M. (1990). The development of a reliable and valid treatment program for aggressive young children. Special Issue: Unvalidated, fringe, and fraudulent treatment of mental disorders. International Journal of Mental Health, 19, 19-26.

Reid, M. J., Webster-Stratton, C., \& Baydar, J. (2004). Halting the development of conduct problems in Head Start children: The effects of parent training. Journal of Clinical Child and Adolescent Psychology, 33, 279-291.

Roberts, C., Mazzucchelli, T., Studman, L., \& Sanders, M. R. (2006). Behavioral family intervention for children with developmental disabilities and behavioral problems. Journal of Clinical Child and Adolescent Psychology, 35(2), 180-193.

Roberts, C. M., Mazzucchelli, T., Taylor, K., \& Reid, R. (2003). Early intervention for children with challenging behavior and developmental disabilities. International Journal of Disability, Development and Education, 50, 275-292.

Sanders, M. R., Mazzucchelli, T. G., \& Studman, L. J. (2003). Practitioner's manual for standard Stepping stones Triple P. Brisbane, Australia: Triple P International.

Sigafoos, J. (2000). Communication development and aberrant behavior in children with developmental disabilities. Education and Training in Mental Retardation and Developmental Disabilities, 35, 168-176.

Snell-Johns, J., Mendez, J. L., \& Smith, B. H. (2004). Evidence-based solutions for overcoming access barriers, decreasing attrition, and promoting change with underserved families. Journal of Family Psychology, 18, 19-35.

Webster-Stratton, C. (2001). The Incredible Years: Parents, teachers, and children training series, leader's guide. Seattle, WA: Author.

Weis, R., Lovejoy, M.C., \& Lundahl, B. (2005). Factor structure and discriminative validity of the Eyberg Child Behavior Inventory with young children. Journal of Psychopathology and Behavioral Assessment, 27(4), 269-278.

Child and Adolescent Mental Health, Vol. 14, No. 4 (November 2009): pg. 183-189. DOI. This article is @ Wiley and permission has been granted for this version to appear in e-Publications@Marquette. Wiley does not grant permission for this article to be further copied/distributed or hosted elsewhere without the express permission from Wiley. 
NOT THE PUBLISHED VERSION; this is the author's final, peer-reviewed manuscript. The published version may be accessed by following the link in the citation at the bottom of the page.

Table 1. Treatment outcomes based on parent and child measures at intake and treatment completion

\begin{tabular}{|c|c|c|c|c|c|c|c|}
\hline \multirow[b]{2}{*}{ Observational Measure } & \multicolumn{2}{|c|}{ Intake } & \multicolumn{2}{|c|}{ Completion } & \multirow[b]{2}{*}{$\mathrm{F}$} & \multirow[b]{2}{*}{ df } & \multirow[b]{2}{*}{$\eta^{2}$} \\
\hline & Mean & SD & Mean & SD & & & \\
\hline Child Behavior Scores & 18.30 & 2.02 & $20.96^{a}$ & 2.91 & 39.65 & 1,66 & .38 \\
\hline Parent Behavior Scores & 20.72 & 3,15 & $23.03^{\prime \prime}$ & 2.65 & 24.95 & 1,66 & 27 \\
\hline \% Compliance to Parental Requests & 36.81 & 25.73 & $74.71^{\circ}$ & 42.87 & 37.37 & 1,48 & 44 \\
\hline Parent Uses Child's Name & 1.53 & 0.68 & $1.78^{b}$ & 0.47 & 4.02 & 1,48 & .08 \\
\hline Parent Praises Child's Compliance & 0.89 & 0.77 & $1.61^{\circ}$ & 0.61 & 33.33 & 1,48 & 41 \\
\hline \multicolumn{8}{|l|}{ Eyberg Child Behavior Inventory } \\
\hline Intensity & 150.06 & 32.97 & $126.23^{\mathrm{*}}$ & 37.61 & 69.03 & 1,90 & .43 \\
\hline Problem & 18.00 & 8.18 & $11.90^{4}$ & 9.88 & 27.02 & 1,90 & 23 \\
\hline \multicolumn{8}{|l|}{ Parent Behavior Checklist } \\
\hline Expectations & 28.39 & 7.50 & $3181^{a}$ & 7.52 & 18.73 & 1,83 & .18 \\
\hline \multicolumn{8}{|l|}{ Table 1 cont. } \\
\hline Discipline & 15.17 & 4.38 & 14.83 & 5.76 & 0.25 & 51,83 & 00 \\
\hline Nurturing & 30.86 & 5.06 & 31.33 & 5.52 & 0.83 & 31,83 & .01 \\
\hline Parent-Child Relationship Scale & 58.34 & 12.41 & $72.54^{a}$ & 13.39 & 114.52 & 21,81 & .59 \\
\hline
\end{tabular}

${ }^{a}$ Indicates significant change $(p<.01)$ from intake to treatment completion.

bIndicates significant change $(p<.05)$ from intake to treatment completion.

Child and Adolescent Mental Health, Vol. 14, No. 4 (November 2009): pg. 183-189. DOI. This article is (c) Wiley and permission has been granted for this version to appear in e-Publications@Marquette. Wiley does not grant permission for this article to be further copied/distributed or hosted elsewhere without the express permission from Wiley. 